\title{
Citizen observatory based soil moisture monitoring - the GROW example
}

\author{
Károly Zoltán KOVÁCS ${ }^{1}$, Drew HEMMENT², Mel WOODS³, \\ Naomi K. van der VELDEN ${ }^{4}$, Angelika XAVER ${ }^{5}$, Rianne H. GIESEN ${ }^{6}$, \\ Victoria J. BURTON ${ }^{4}$, Natalie L. GARRETT ${ }^{7}$, Luca ZAPPA ${ }^{5}$, Deborah Long ${ }^{3}$, \\ ENDRE DOBOS ${ }^{1}$ and RASTISLAV SKA LSKY ${ }^{8}$
}

\begin{abstract}
GROW Observatory is a project funded under the European Union's Horizon 2020 research and innovation program. Its aim is to establish a large scale (more than 20,000 participants), resilient and integrated 'Citizen Observatory' (CO) and community for environmental monitoring that is self-sustaining beyond the life of the project. This article describes how the initial framework and tools were developed to evolve, bring together and train such a community; raising interest, engaging participants, and educating to support reliable observations, measurements and documentation, and considerations with a special focus on the reliability of the resulting dataset for scientific purposes. The scientific purposes of GROW observatory are to test the data quality and the spatial representativity of a citizen engagement driven spatial distribution as reliably inputs for soil moisture monitoring and to create timely series of gridded soil moisture products based on citizens' observations using low cost soil moisture (SM) sensors, and to provide an extensive dataset of in situ soil moisture observations which can serve as a reference to validate satellite-based SM products and support the Copernicus in situ component. This article aims to showcase the initial steps of setting up such a monitoring network that has been reached at the mid-way point of the project's funded period, focusing mainly on the design and development of the $\mathrm{CO}$ monitoring network.
\end{abstract}

Keywords: citizen science, citizen observatory, crowdsourced data, soil moisture monitoring

\section{Introduction}

Environment-related pressure on our society is intense. The attentive use and management of environmental resources are crucial for future generations' prosperity. Better observation, understanding, protection, and enhancement of our environment is only feasible with the active involvement of citizens. Although our political, economic and administrative structures may be designed to tackle our environmental concerns through scale and strategic decisions, citizens often feel as though they are un-engaged, silent observers (McGlade, J. 2009; LiU, H.Y. et al. 2014). Formal institutions like EU Water Framework Directive, Flood Risk Directive and

\footnotetext{
${ }^{1}$ Institute of Geography and Geoinformatics. University of Miskolc. H-3515 Miskolc, Egyetemváros. E-mails: ecocares@uni-miskolc.hu, ecodobos@uni-miskolc.hu

${ }^{2}$ University of Edinburgh, E-mail: drew.hemment@ed.ac.uk

${ }^{3}$ University of Dundee. E-mails: m.j.woods@dundee.ac.uk, d.long@dundee.ac.uk

${ }^{4}$ Permaculture Association (Britain). E-mails: naomi@permaculture.org.uk, victoria@permaculture.org.uk

${ }^{5}$ Department of Geodesy and Geoinformation, TU Wien, Gußhausstraße 27-29, 1040 Wien, Austria. E-mails: angelika.xaver@geo.tuwien.ac.at, luca.zappa@geo.tuwien.ac.at

${ }^{6}$ HydroLogic Research, Delft, The Netherlands, rianne.giesen@hydrologic.com

${ }^{7}$ Met Office, United Kingdom, natalie.garrett@metoffice.gov.uk

${ }^{8}$ International Institute for Applied Systems Analysis, Laxenburg, Austria skalsky@iiasa.ac.at
} 
the Aarhus Convention require citizen participation. Despite the long history of 'Citizen Observatory' (CO) quality assurance for the scientific use of citizen science generated data is still missing (Freitag, A. et al. 2016). Nevertheless, robust examples exist, such as, The National Audubon Society Christmas Bird Count which has been running since 1900 in North America, the data collected by observers over the past century allow researchers, conservation biologists, wildlife agencies and other interested individuals to study the long-term health and status of bird populations across North America (Butcher, G.S. et al. 1990; НоснаснкA, W.M. et al. 2012).

The chosen subject of observation itself has an influence on how successful a citizen observatory will be. Examining the motivations of citizen science participants can give insights into why certain initiatives are more successful than others (Clary, E.G. and SNyder, M. 1999; Rotman, D. et al. 2012; Geoghegan, H. et al. 2016). Citizen science projects are dominated by biodiversity topics rather than the abiotic environment (Рососк, M.J.O. et al. 2017), possibly because experiencing and improving the environment is a common motivator of citizen observations (WEST, S.E. 2015). Weather and climate is also a popular topic (GHARESIFARD, M. et al. 2017) because this has an impact on citizens' everyday life. Sufficient data and validation have been collected to initiate commercial applications for citizen observation data in weather forecasts.

The GROW Observatory monitors soil properties, aiming to engage a target audience of smallholders, and community groups practicing sustainable growing. The participants' motivation is mostly focussed on: improving their immediate environment; growing crops; getting the most out of their land through sustainable practices, without harming the environment and concerns about soil degradation. Emotional motivation is evident for the stakeholders, but to engage and train participants to generate an observation dataset of high scientific standards poses challenges. GROW Observatory during the funded period of the project aims to organize a $\mathrm{CO}$, which is viable after the funded period. To engage and train core groups of stakeholders all over Europe is a must to reach this goal. The first half of the project was to establish the framework, develop the training and communication tools and strategies, to define and engage communities around Europe.

As soil formation is slower than the humaninduced degradation processes, it can be considered a non-renewable or a conditionally renewable resource. To sustainably manage soils over a large geographic scale, sophisticated environmental monitoring infrastructure is required and society of environmentally conscious citizens. By the continuous observation and documentation of our environmental conditions, both regular individuals and scientists can learn the impact of the related activities. Awareness raising is one of the most important goals of the GROW Observatory project.

The soil has various physical, chemical and biological properties, which define its ability to support its functions. Soil moisture is the amount of water present in the soil. It defines the thermal buffering capacity of warming and cooling the environment, the amount of available water for biomass production. Soil is a reservoir of a significant amount of continental freshwater from the water cycle as well. Soil moisture is an ever-changing property of the soils. It is influenced by climate, soil texture and structure, organic matter content and above all land use and land-cover (VÁrALLYAY, G. 1989). Detailed observation of the spatial and temporal distribution and variation of soil moisture is fundamental for drought and flood modelling, global climate predictions or the precise use of agricultural land (VÁRALLYAY, G. 2010). Soil moisture serves as a key input parameter in wind and water erosion estimations and is a driving parameter of soil biological activity and diversity, organic matter development, hence carbon sequestration (Lavelle, P. et al. 2006). One of the biggest threats to agricultural land is soil compaction and soil moisture is a principal parameter influencing soil strength, so it is a particularly helpful characteristic when assessing the likely magnitude of the soil shearing resistance and 
hence the inherent vulnerability of subsoil to compaction. Long term soil moisture measurements describe the soil moisture regime, which defines salinization processes on salt-affected soils. For these reasons and more, it is extremely important for soil moisture to be measured.

In situ measurements have been historically used as the main source of information on local moisture conditions (VÁRALLYAY, G. 1994; Maкó, A. et al. 2010). Several techniques have been developed for measuring in situ soil moisture, each having specific advantages, characteristics and measurement accuracy (Robinson, D.A. et al. 2008; Dorigo, W.A. et al. 2011b). The most commonly used instruments measuring soil moisture over a small area which hence were the only representative of the conditions a few centimetres around the sensor. Even though a large number of local and regional soil moisture networks are operating worldwide, they lack common standards (e.g. observed variables, sensor types, sensor setup, etc.) and the generated data are often not freely available. The International Soil Moisture Network (ISMN, https://ismn.geo.tuwien.ac.at/) (Dorigo, W.A. et al. 2011a, b) is an international initiative trying to overcome such issues. In situ soil moisture observations are collected from various networks distributed all over the globe, harmonized in terms of the sampling interval, units, and data format and made freely available to the public through a web portal (IPCC, 2007). In Europe, there are fewer than 250 stations available in the ISMN providing information about the water content of the soil. It is, therefore, evident that there is great potential offered by COs (e.g. GROW) to contribute with an unprecedented stream of data from thousands of sensors. Nevertheless, European-wide and global analysis based on ground observations would remain challenging because such measurements are spatially sparse. Due to the high spatial variability of soil moisture, a huge number of stations would be necessary. However, the high costs related to installation, operation and maintenance of the sensors, as well as the limited accessibility of certain regions, make the setup of such a network not feasible (Gruber, A. et al. 2013).
To fill this gap, remotely sensed data from optical/thermal and microwave instruments are being used to retrieve soil moisture globally (WANG, L. and QU, J.J. 2009). In particular, microwave sensors, both active and passive, have proven successful for estimating dielectric properties of soil, thus, leading to the estimation of soil moisture (MoHANTY, B.P. et al. 2017). Furthermore, when compared to opti$\mathrm{cal} /$ thermal sensors, microwave remote sensing has the great advantage of observing the Earth's surface independently from the weather (i.e. cloud cover) and solar conditions (i.e. both during day and night). Several satellitederived datasets have been available for the last two decades, providing long-term records of global soil moisture conditions. The use of coarse-scale observations $(10-50 \mathrm{~km})$ from active or passive sensors is well established and used for operational purposes. For example, remotely sensed soil moisture products from the Advanced Scatterometer (ASCAT) aboard Metop (WAgner, W. et al. 2013), the Soil Moisture and Ocean Salinity (SMOS) (KERR, Y.H. et al. 2012) and Soil Moisture Active Passive (SMAP) (CHAN, S.K. et al. 2016) missions have been extensively evaluated and found widespread use (Grainger, A. 2017; Bauer-Marschallinger, B. et al. 2018).

However, such coarse scale products do not meet the requirements of many applications, such as irrigation management, erosion/ landslide prediction, and catchment-scale hydrologic processes. The recently launched Sentinel-1 mission is scanning the Earth's surface at unprecedented spatial resolution (backscatter retrieved at $20 \mathrm{~m}$ ). In particular, Sentinel-1 is a mission of the European Earth observation program Copernicus, consisting of two identical satellites, Sentinel-1A and Sentinel-1B, launched in April 2014 and April 2016 respectively, and carrying a Synthetic Aperture Radar (SAR) system. The soil moisture retrieval from Sentinel-1 poses some challenges because of the complex influence of terrain roughness and vegetation on the backscattered signal and is, therefore, available at a 1 $\mathrm{km}$ spatial resolution (BAUER-MARSCHALLINGER, B. et al. 2018). This product is currently in prep- 
aration for operational dissemination through the Copernicus Global Land Service (https:// land.copernicus.eu/global/products/ssm). Regardless of the sensor used to estimate soil moisture, satellite-derived products are becoming more and more valuable for local to global monitoring of the Earth status. The calibration of algorithms and validation of products are of vital importance, therefore, so too are spatially distributed in situ monitoring networks providing long-term reference measurements (Mohanty, B.P. et al. 2017).

The GROW Observatory aims to demonstrate a CO can deliver widespread uptake, robust science, societal impact, and by prototyping new innovative services, be a sustainable business model for long-term operation. Citizens' Observatories are a concept developed at the European Union (EU) level. COs are communities of stakeholders which include citizens, scientists, policymakers and others collaborating on research, and in this case for environmental monitoring, whose issues have impacts related to land cover and land use. A soil moisture participatory monitoring network is a step forward in environmental monitoring. A European-wide network of stakeholders interested in the state of soil on local, regional, national and EU level generates not only data and other observations but also discussion and knowledge-sharing related to soil protection, land use, soil conditions, and climate monitoring, documentation on growing practices and harvest data. The basis for the professional and scientific framework of the dialogue of participants of the $\mathrm{CO}$ is provided by the widespread and accurate communication and training materials, face-to-face workshops. The value of the common knowledge generated by the $\mathrm{CO}$ is worth as much for the community as much the generated quality data is important for science.

\section{Methods and procedure}

Functional citizen observatories can take a number of routes to development, many are bottom-up initiatives developing organically to address a matter of environmental concern, with an initial momentum. To address the specific scientific needs, the GROW Observatory is taking the example and top-down organizes a soil moisture citizen-based monitoring network. Demand exists for the science part, and for part of professional land users also, the formulation of the real return value is still a must.

The GROW Observatory set out to demonstrate a complete 'Citizens' Observatory' system for monitoring SM, land use and landcover, contributing in situ data for satellite validation, creating useful data products and applications, and overcoming barriers to uptake. GROW entails a particular approach to mobilizing citizens and stakeholders from science and policy in data collection, data awareness, and data innovation. This approach was described and formalized in the first year of the project as a framework, in order that it can be effectively developed, evaluated and replicated. The GROW citizens' observatory framework is here proposed as a process model underpinned by four cross-cutting values. Together these documents an ideal and conceptualized representation of the GROW Citizens' Observatory (Figure 1, Table 1).

One of GROW's distinguishing features among other projects is its aim is to focus on 'closing the loop', moving from citizen issues

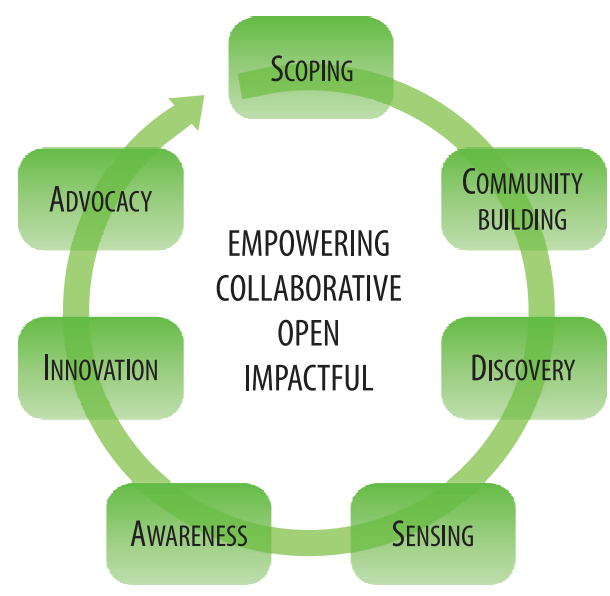

Fig. 1. GROW Citizens' Observatory model 


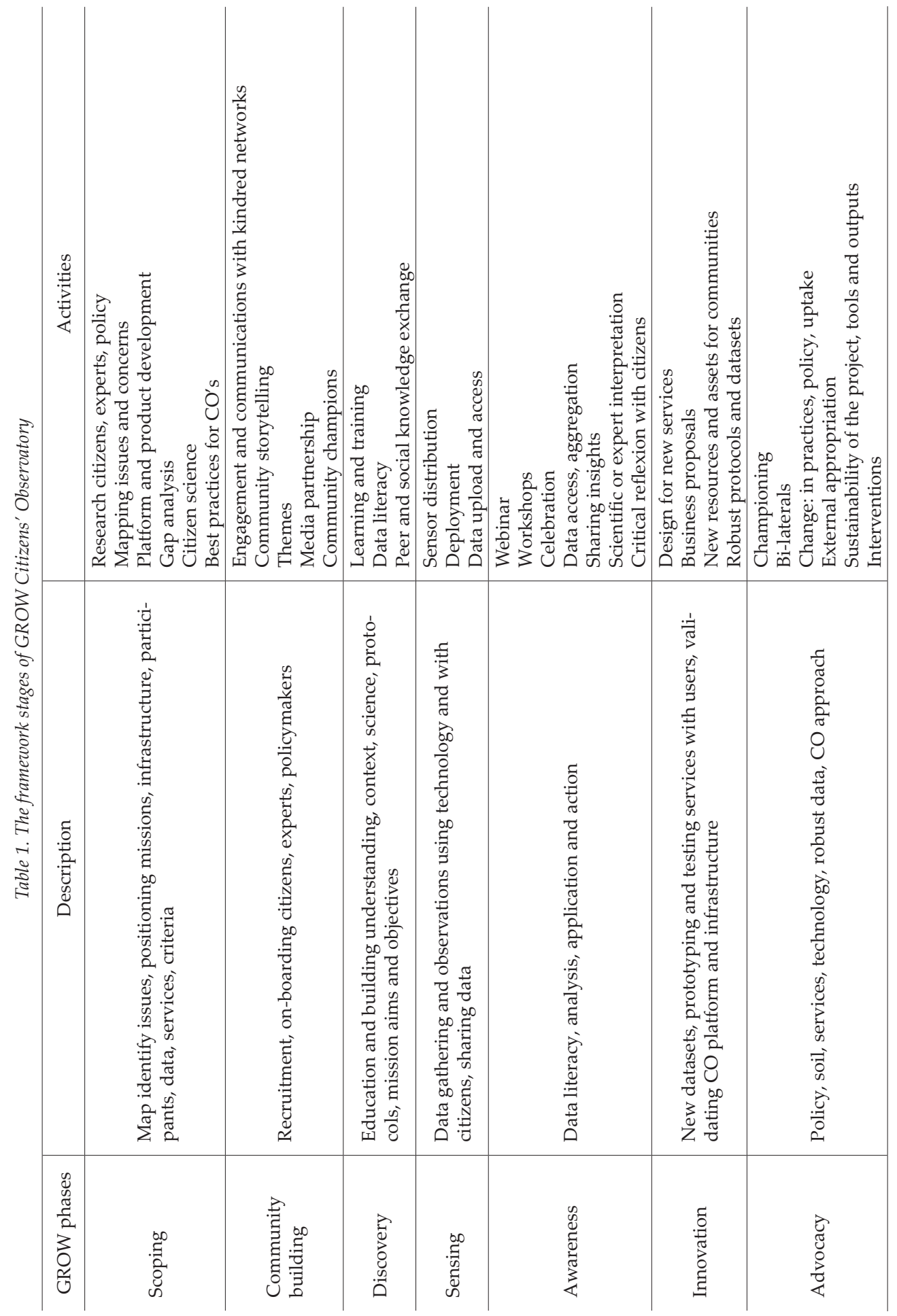


and data collection to development of critical innovative services with the value given back to citizens, experts, and policymakers. The challenge generally for COs is moving from a top-down contributory model of citizen science to a more distributed model, and to sustain community building and engagement throughout the project cycle. The GROW Model structure outlined in Figure 1 provides a mechanism to develop and overview the whole cycle and set the direction when planning, developing, delivering and evaluating the primary steps to:

1. generate, share and utilize data and information presented and adapted to a range of stakeholders;

2. address community, science and policy challenges;

3. innovate in services using GROW data for land and soil issues of participants: citizens, decision-makers and scientists.

\section{Results, the concept and elements of GROW}

Having used the model described above, the following major elements and tools have been developed to support the public engagement process and to structure the sensor data and the important covariates provided by citizen science activities into a functional platform to store the data and make it publicly available for any further scientific or commercial use. The monitoring system has two main factors influencing the final database quality. The human factor is the depth of engagement, the level of knowledge and interest. The backend system and sensor infrastructure is the technical factor. The results are grouped and presented in these contexts.

\section{Elements of engagement tools developed and integrated into the procedure}

\section{GROW Missions}

The definition of a GROW Mission is a period of coordinated citizen science activity, that can involve observations, sampling, and sense-making, designed to deliver a clearly stated output linked to a GROW ambition. Each Mission represents a complete cycle through the seven stages of the GROW Framework. GROW Missions bring together a community of citizens and stakeholders in science and policy to collaborate on research for environmental monitoring, whose issues have impacts related to land cover and land use. Pilot Missions were delivered in the first year of the project to test project concepts and infrastructure, and two main Missions were then defined from year two of the project:

a) Changing Climate Mission

This mission is open to those located in 9 GROW Places which were selected using key criteria through an open call. We are focusing the sensors in a limited number of areas because a high density of measurements is the most valuable to science. Additionally, there is a limited supply $(15,000)$ of the lowcost soil sensor we are using in GROW. In this mission, we are deploying several thousand soil sensors around Europe, which send soil moisture data back to the GROW Observatory. These data are used to validate soil moisture readings taken by European Space Agency satellites and to inform decisions by food growers and policymakers, ultimately the ambition is to help society adapt to extreme climate events.

b) Living Soils Mission

This mission is open to anyone, anywhere. The aim is to develop and support an active network of small-scale growers and gardeners who grow food by using and collaboratively investigating, practices that regenerate soils and create resilient ecosystems. Two key elements are the provision of scientifically robust information on selected regenerative practices such as using mulches, reducing digging or tilling, and growing polycultures via free massive open online courses (MOOCs). This was combined with a citizen experiment on polycultures called the Great GROW Experiment, which was designed to enable individual growers to investigate whether growing three crops together in a polycul- 
ture or separately in monocultures was more productive. A final element is the sharing of planting and harvesting times for key crops to improve localized growing advice available in the GROW Observatory App.

\section{GROW Places}

GROW Places (GP) are an innovation for the delivery of a CO sensor network. They contribute to the mission of delivering a viable, high-density distribution of sensors across geographically diverse areas, using geographic and scientific criteria, designed for scientific exploitation, and enabled by the participation of a place-based community. GROW Places were specified as focus areas for citizen science activity, that provide GROW with a mechanism to establish direct contact with local growing communities in Europe (Figure 2). They have been defined as a solution for sensing activities and to meet the geospatial requirements of the 'gridded product'. Up to 15,000 Flower Power soil sensors (Parrot Drones SAS, Paris, France) are available to participants in GROW Places. These are a formally commercially available product, a detailed description can be found in Description and technical details of the sensors used in GROW Observatory.

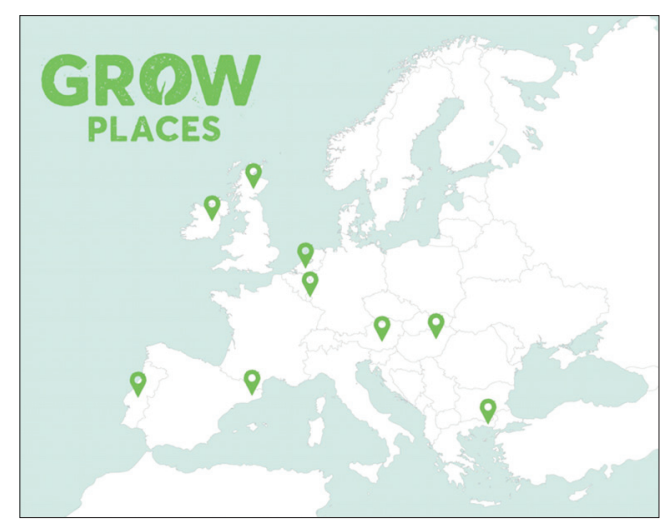

Fig. 2. GROW Places around Europe
GROW places are carefully selected areas where the capacity of engagement and the spatial and technical requirements of the soil moisture monitoring network meet. To create a representative spatial coverage of sensor deployment a clustered-nested monitoring network was designed. The GROW Place areas represent the regional heterogeneity of Europe, selected by climatic regions. Within these $50-100 \mathrm{~km}$ wide windows, there are the local clusters nested, which cover the topographic, microclimatic and soil heterogeneity. The degrees of freedom of the networks' coverage is limited by the available stakeholders and clustering communities, but this way of constructing the network can provide results from the beginning. The details of the selection method described in Spatial coverage, the relation of observation network development and engagement process.

\section{Community Champions}

Community Champions (CC) are 'ambassadors' on the ground. They support local community participants through the provision of a sensor and materials needed for the sensing survey as well as 'meet-ups' to provide support and training for participants. Through the Community Champions, GROW is able to build a network of engaged participants in each GROW Place. CCs are the regional organizing force on each GPs, they are directly and continuously connected to project partners, feedback and action are through CC organization.

\section{Online Community}

GROW's online community is central to meeting GROW's ambitions to engage thousands of people in sustainable soil management and food growing. The online community has access to training materials, information sheets and support materials. Our communication strategy brings novelty through the application of the 'Storytelling method'. Through GROW's online commu- 
nity and tools (discussion forum, knowledge base, learning platform, social media), users can upload and explore data, discuss findings and share stories. The aim is to promote deeper engagement - as the primary goal is for the participants to talk to, learn from and support each other, rather than receiving top-down information from the GROW team.

\section{Experimenters' community}

The Great GROW Experiment, part of the Living Soils Mission took a different approach to engage and work with the community. It delivered an innovative hypothesis-driven rather than an observation-based approach to citizen science. This was founded in training citizens in how to do research in their growing space as well as in how to implement the experiment and interpret their own results. As such, it requires the intensive investment of both time (across the growing season) and growing space for participants and is likely to attract fewer participants than simpler observation-based approaches (BonNEY, R. et al. 2009). Experimenters were supported from May to October 2018 with regular emails, a dedicated online forum, and monthly live meetings where they could learn from the scientists running the experiment and share insights with each other. MOOC courses assisted in training citizens, culminating in helping experimenters to graph and understand their own experiments. This approach not only enhanced a sense of community and learning, but also provided valuable insights into the progress of the experiment, issues with crops, and technical limitations for data input. In later online meetings and in the final MOOC, initial results were shared and discussed, allowing participants to contextualize their own findings with those of others. We have observed this approach achieved a high level of deep engagement, for the participants. This committed small group of individuals is making clear plans for continuing experimenting on their own and involving their communities.

\section{Online learning - GROW Massive Open Online Courses (MOOCs)}

An innovative element of GROW is providing rigorous training for citizens in scientific protocols for data collection. This is seen as an approach to improve data quality and validity by enabling cohorts of citizens to receive training and grow their confidence in providing data. Data quality of measurements is a particular challenge in citizen science (HECKER, $\mathrm{S}$. et al. 2018), especially with a large number of participants distributed over a wide area, or even an entire continent. It is widely acknowledged that the ways in which citizens learn and gain knowledge are changing, with new tools and educational materials available to foster citizens' autonomy and responsibility for change through lifelong learning. In addition to training in techniques, each MOOC also offers a recruitment opportunity. It builds a cohort of learners who become familiar with GROW's aims and activities and who can access and sign up the GROW Observatory's wider activities outside the MOOCs. Online learning is the tool of quality assurance and also important in raising interest, develop communities and cluster common knowledge.

\section{Elements of database development}

The data provided by the $\mathrm{CO}$ is the output and the tool for further engagement. The quality and applicability of the resulting database is the best measure of the COs functionality. In order to structure the contributions and make them accessible for any further use, the following tools and elements were developed and integrated into the framework.

\section{Data quality assurance and data governance}

\section{Sensing Handbook and Sensing Manuals}

The Sensing Handbook and Sensing Manuals are printed and downloadable 
training resources in use by participants, translated in the local language of GROW Places, that communicate the Mission objectives and instructions for:

- identifying a suitable location for the sensor;

- placing and registering the sensor;

- carrying out the land survey;

- troubleshooting and accessing support.

\section{Sensing infrastructure}

The GROW Observatory aims to set-up a pilot citizen soil moisture monitoring network with 15,000 deployed sensors EU-wide from the beginning. The data, generated by the CO will be incorporated in GEOSS and used to validate for soil moisture SAR remote sensing data. The gridded product creation and Sentinel-1 soil moisture model ground-truthing were the two main aims for GROW soil moisture data. The scientific criteria and quality assurance were designed to satisfy these aims and form the basis of the soil moisture sensing aspect of the CO. The intention is to develop the platform further to connect other brands and do-it-yourself (DIY) soil sensors.

The upper $10 \mathrm{~cm}$ of soil dynamic properties vary fast in time and highly within a small area. Sensor measurements' inaccuracy can be dissolved in the real range of values. To be aware of the quality of the generated database the sensors were tested two ways. One is against professional, calibrated probes and the other is in the laboratory, measuring real values of water content as described below.

The Flower Power sensor logs soil moisture, soil surface temperature, light intensity, and conductivity measurements every 15 minutes. The device can store 80 days' worth of measurements which is accessed with a mobile app through low energy Bluetooth connection. The application to connect the sensor to mobile devices only runs on Android and iOS systems. Batteries will last for 6 months in summer and 4 months in the winter period, on average (depending on temperatures).

The measured values are:

- Air Temperature (Range: $-5{ }^{\circ} \mathrm{C}$ to $+55^{\circ} \mathrm{C}$; Accuracy: $\left.+/-1.5^{\circ} \mathrm{C}\right)$.
- Light (Range: 0.13 to 104 [mole $\times \mathrm{m}^{-2} \times \mathrm{d}^{-1}$ ]; Accuracy: $+/-15 \%)$. The light sensor is calibrated to measure Photo-synthetically Active Radiation (PAR), defined as light in the wave length between 400 and $700 \mathrm{~nm}$.

- Soil Moisture (Range: 0 to 50 [v/v \%]; Accuracy: +/-3\%).

- Fertilizer level / Conductivity (Range: 0 to $10\left[\mathrm{mS}^{\circ} \mathrm{cm}^{-1}\right]$; Accuracy: $+/-20 \%$ ).

The soil moisture measurements are the main focus of the $\mathrm{CO}$, but the other values documented give good environmental data of the current state of soil and weather. Information about the sensor location is generated the first time data are uploaded using an internet connection from the device to the Parrot cloud. This can generate inaccuracy in the geolocation entered in the database since the internet connection is needed at the sensor location. The ability to amend sensor coordinates is included in the Collaboration $\mathrm{Hub}(\mathrm{CH})$ but requires a European wide campaign to train and motivate users to use it.

3. Quality check of sensing infrastructure

FP sensor performance compared to professional probes.

In order to evaluate the performance of the Flower Power soil moisture sensors, they were placed alongside professional probes in two different study areas, located in Austria and Italy. The main study area is the Hydrological Open Air Laboratory (HOAL, http://hoal.hydrology.at; BLöschL, G. et al. 2016) located in Petzenkirchen, Austria. HOAL is an agricultural catchment covering 66 ha and equipped with soil moisture stations (20 permanents and 11 temporaries). The permanent stations are located in pasture and forest, while the temporary stations are installed in agricultural fields and are removed on a regular basis to allow for field management. The majority of the stations are equipped with SPADE Time Domain Transmission sensors, one station uses the Decagon 5TM sensor to measure soil moisture. The sensors are installed in a horizontal position at different depths: $0.05 \mathrm{~m}, 0.10 \mathrm{~m}$, $0.20 \mathrm{~m}, 0.50 \mathrm{~m}$ and $1.00 \mathrm{~m}$. In addition, there are two professional soil moisture stations 
installed $20 \mathrm{~km}$ North of Petzenkirchen, in Dietsam, Austria. They are located in grassland and equipped with Decagon 5TM sensors in a depth of $0.05 \mathrm{~m}$ and $0.10 \mathrm{~m}$.

A total of 37 Flower Power soil moisture sensors were placed on the $30^{\text {th }}$ of April 2017 alongside the technical grade sensors in the HOAL catchment, four on the $24^{\text {th }}$ of May 2017 in Dietsam. Up to the beginning of 2018, 7 additional sensors were placed in Petzenkirchen and 3 sensors had to be replaced in Dietsam. In total, 51 Flower Power sensors were used to evaluate their performance in comparison to 31 professional probes in Austrian test sites. The Flower Power sensors are installed vertically, providing information about the water content of the first ten centimetres of soil. The comparison period between professional and Flower Power sensors ranges from 2 to 10 months (due to different installation dates and/or removal caused by field management practices).

The second study area consists of two sites located in Umbria, Italy. The first site 'Petrelle' is part of the network 'UMBRIA' (BRocCA, L. et al. 2011), which is part of the International Soil Moisture Network (ISMN, http://ismn. geo.tuwien.ac.at/; Dorigo, W.A. et al. 2011a, b 2013). The 'UMBRIA' station is equipped with ThetaProbe ML2X sensors, installed vertically (0.05-0.15 $\mathrm{m}$ and $0.15-0.25 \mathrm{~m})$. The second site consists of two professional stations of the net- work 'HYDROL-NET_PERUGIA' (MORBIDELLI, R. et al. 2014), which is part of the ISMN as well. At these professional stations, TDR TRASE sensors are horizontally installed at a depth of 0.05 m. 2 Flower Power sensors were installed next to one professional probe from the 'UMBRIA' network and 4 Flower Power sensors were installed alongside two professional stations of the network 'HYDROL-NET_ PERUGIA'. The Flower Power sensors were installed in the middle of November 2017 and provided data for more than two months.

As shown in Figure 3 good agreement of the temporal variability between the Flower Power and the professional soil moisture sensors can be observed in both study areas. For the sensors located in Austria, a stronger response of the Flower Power sensors to precipitation events is visible which can be explained by the different sensor positioning. A more or less pronounced bias between the soil moisture levels from the low-cost and the professional probes can often be observed, and is not surprising due to the lack of site-specific calibration of the Flower Power sensors.

However, for satellite validation, the soil moisture relative variability is of higher importance than the absolute values. Therefore, the scientific goals of GROW remain inviolate, but accurate measures of absolute water content in the soil would be more valuable for farmers and growers.

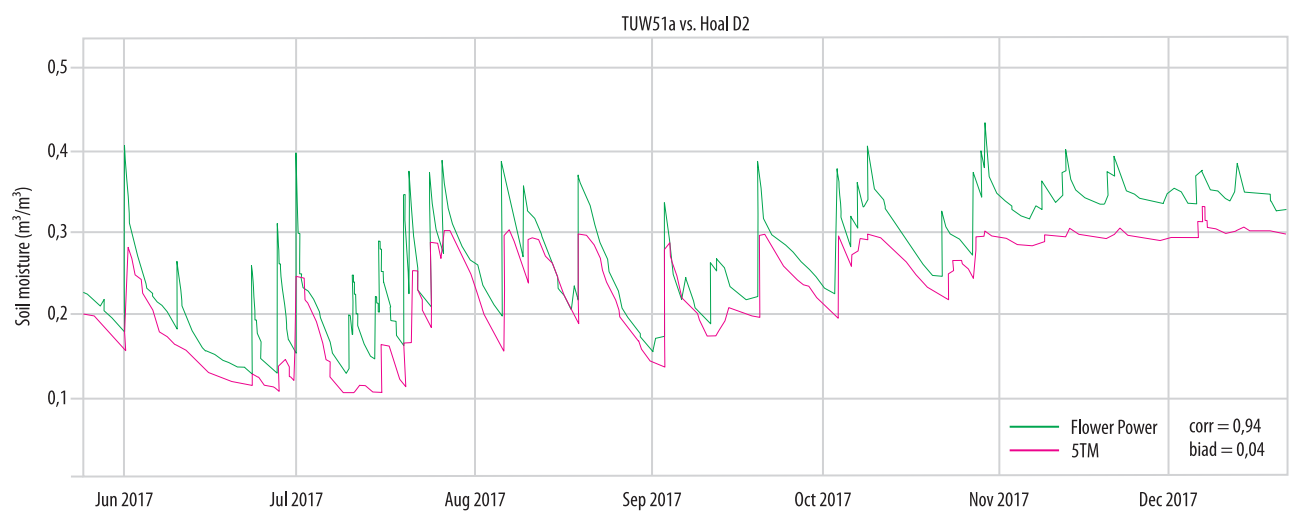

Fig. 3. Time series plots of Flower Power and 5TM (0.10 m depth) soil moisture readings in Dietsam, Austria 
4. Laboratory testing of Flower Power sensors Flower Power sensors were validated in laboratory conditions in four different kinds of soils and two different setups; 28 sensors were deployed on four different kinds of soils (seven sensors for each: clay loam; sandy loam; loam; loamy sand). Two different experimental setups with four sensors were installed into the same container for cross-validation and three sensors were installed in separate containers with large diameters to test the measured soil volume and for cross-correlation.

First, four different types of natural soils were selected and prepared and laboratory tested for basic chemical and physical properties. The volume of the samples was measured and recorded and then the soil was saturated with water and the weight of saturated soil recorded. The saturated soil samples were dried naturally for 31 days in an undisturbed room and the weight was measured each day with exact time records. The actual soil moisture content was calculated for each measurement and the measured values were compared with the downloaded Flower Power sensor data for the same time. Statistical analysis to define the measurement uncertainties and its soil type dependencies were performed. Conclusions were that there is a clear correlation in the levels of uncertainty identified. Flower Power sensor measurements on dryer soils have larger positive divergence from the actual measured value, of around 40 per cent moisture content and overestimated moisture when below 40 per cent actual value, and underestimated it above 40 per cent actual soil moisture. The cross-validation among the sensors was more or less constant, except in very dry conditions due to the cracking of the soil. Flower Power measurements had a severe distortion in dry soil moisture conditions $(<20 \%)$ and can almost double the real value.

In the most common soil moisture range ( $20 \%$ to $40 \%$ ), the estimation differences are less than 20-25 per cent. Within the sensors, variation does exist but is negligible, but cross sensor variation can reach 15 per cent. The deviation from the lab measured values show a very strong trend line - the deviation increases towards the dry section. There are significant differences between the different soil types, but the same trends can be observed in Flower Power sensor measurement uncertainty (Figure 4).

The sensors performance measuring the real water content was not so reliable, but sensitive enough to detect spatial variability of soil moisture. Measurements for direct

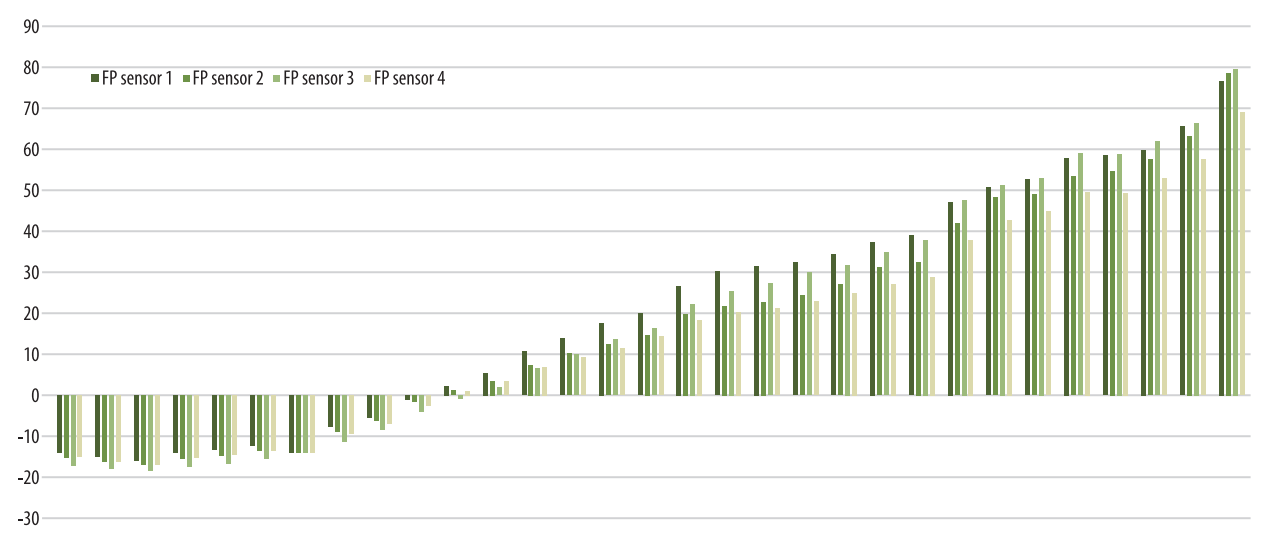

Fig. 4. Deviation from the laboratory measured soil moisture, based on four repetitions of FP sensor measurements for all conditions 
agricultural decision making are not sufficiently accurate, but by empirically the sensor user can get information as within sensor variation is negligible. The purpose of creating continuous soil moisture maps by extrapolation gives some difficulties but to represent spatial variability of soil conditions the sensors are suitable. Other parameters measured by Flower Power sensors were not validated as soil moisture is the primary dataset to be used for the project aims.

\section{GROW Observatory mobile app}

The GROW App provides three services to growers: it provides a local growing, planting and harvesting advice for small scale growers, gives practical information on specific growing approaches that will also improve soils and ecosystems, and it allows the submission of site description for the Changing Climate mission. Information on suitable crops is derived from GROW's Edible Plant Database and is interrogated based on the phone's GPS to show crops that are suitable for the location and time of the query. Each crop has detailed information on site requirements and cultivation. The practice-based information highlights the value of specific regenerative practices as well as guidance on how to implement them. The site information data gives step-by-step guidance for a consistent land-survey for the placement of each sensor including the categorization of side position, slope, canopy cover, and aspect-oriented site photos to enable a consistent comparison of sites.

\section{Data platform development}

The data collected in GROW is made available to growers and other interested stakeholders through the GROW data platform (Figure 5). The two GROW front-end services, the Collaboration Hub and the GROW Observatory mobile app, are both connected to the GROW user account database. This ensures that participants can use their GROW user account for both services and data collected by the user through different channels can be combined. Data from the Flower Power sensors is collected in the field using the Flower Power mobile application. After a Flower Power account has been created in the mobile application, it connects to the sensor via Bluetooth and uploads the data to the Flower Power database.

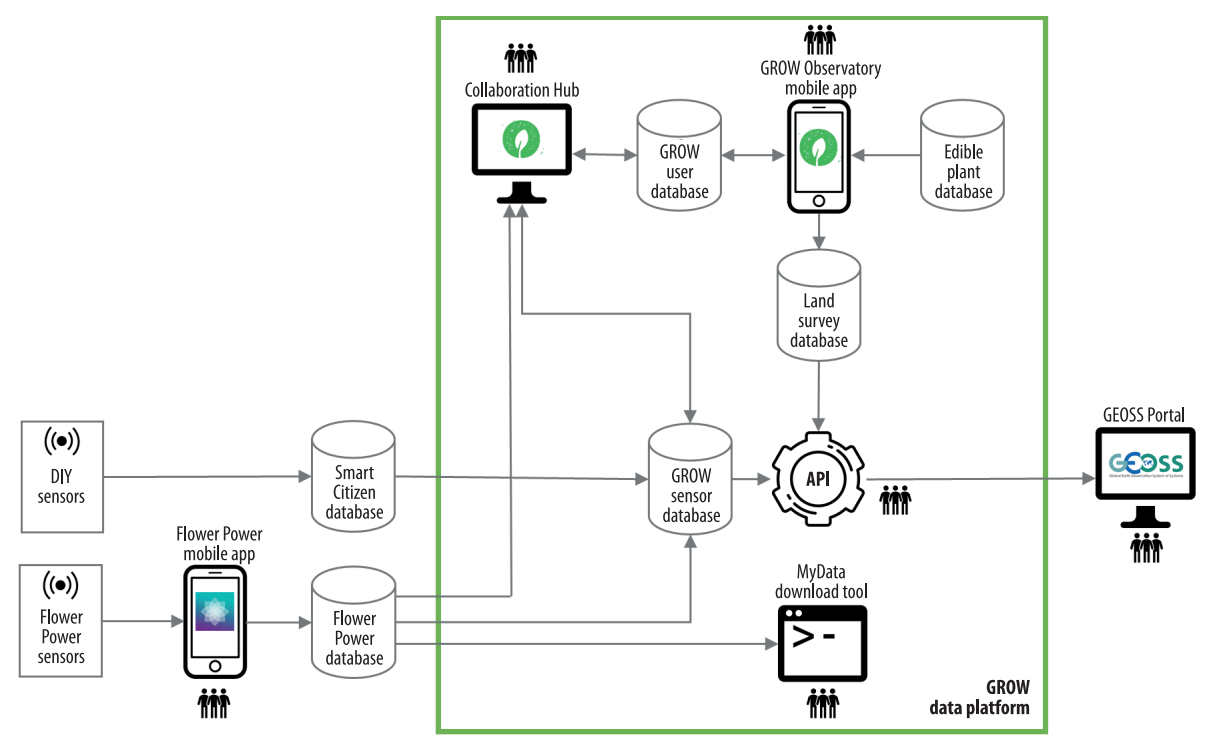

Fig. 5. The GROW data platform (in the green box) and connected external applications and tools 
Growers register their sensor with GROW through their user account in the Collaboration Hub. After successful registration, the GROW sensor database starts to request and store all sensor data collected by the user from the Flower Power database. The Collaboration Hub requests these data from the GROW sensor database and displays them in the user's personal pages. The visualization includes line graphs of the sensor observations and a map with the sensor location. If the location is not correctly registered, users can adjust their sensor location in the Collaboration Hub and the corrected location is saved in the GROW sensor database.

The GROW Observatory mobile app requests information about suitable plants for the user's location and time of year from the Edible Plant Database. Data collected in the mobile app by users performing the land survey is stored in the Land Survey database.

Scientists and companies interested in working with the data collected in GROW can access all data or a selection based on geographic extent or time span through the GROW API. These data are also discoverable through the GEOSS Portal (http://www.geoportal.org/), where Earth Observation data from archives all over the world can be searched.

Individual users who would like to access the sensor data they collected, can use the MyData download tool. This is a simple program that asks the user to provide the username and password of their Flower Power account, after which it requests all data for this user from the Flower Power database. For each sensor that the user owns, the program creates a text file with the data.

7. GROW Data Governance and Infrastructure

Standards and infrastructure are central to GROW - or, indeed, to any CO - and need to be developed and maintained beyond the life of an individual project. GROW is underpinned by standards and infrastructure that are detailed below. The values of GROW relating to handling and sharing data are set out in the GROW Data Governance statement. These, in turn, reflect the core values of the project.

\section{Service Innovation}

Through innovation, GROW aims to deliver services based on collaborative data to enhance the GROW experience for its stakeholders and create an interface with specialist data users in science, policy, and business. Through a human-centred design approach, the needs and interests of users and specialist audiences in science, industry, and policy were scoped in the early stages of the project. This user research underpins service design and development to achieve an effective transfer of environmental knowledge to policy and other specialist communities and the widespread uptake of GROW data and information.

\section{Observatory Policy Interface (OPI)}

One of GROW's aims is to promote and enable more effective and inclusive participatory governance around the management of soils. Soil-related problems are complex, uncertain, multi-scale and impacts upon multiple actors and stakeholders. The OPI helps to inform the underlying assumptions and resulting assertions to establish how participants can inform policy through data gathering and active engagement. This is supported by leveraging established relationships with the policy community to communicate findings to policymakers and forums.

\section{Data dissemination and visualization}

The Collaboration Hub $(\mathrm{CH})$ is a place to be part of the GROW community and to connect and discuss with other stakeholders. It is where people connect their soil sensors to the GROW database and where participants can visualize and compare their observations to regional and local environmental data.

Data visualization and interpretation is one of the project's most important tool of engagement, education and raising interest. Most participants operating sensors are generally aware of the soil conditions of their property and can manage this instinctively by experience. But the recorded dataset, which documents the changes and anomalies throughout time, offers a higher level of knowledge. The $\mathrm{CH}$ is the platform where the recorded and interpreted soil moisture data and the participants' knowledge and 
experience are joined together. Local groups can discuss and analyse the measured values, participants of different professional levels interpret their soil conditions.

\section{Interpretation of measured soil moisture}

Different levels of data visualization have been developed within the GROW Project. The first encounter with the measured soil moisture data occurs when a user connects the sensor with the smartphone to download the logged measurements. The Flower Power smartphone application connects to the sensor, downloads the data and then uploads to the service provider's data storage cloud. On the server side, averaging is made to make the dataset scalable then the processed dataset is downloaded to the device, where a scalable graph view visualizes the measured values. The app contains a global plant database of 7,000 species and varieties and the graph view compares the actual values to the plants' water, light and temperature needs.

Further data visualizations are planned for GROW's CH so participants can compare their observations to regional and local environmental data. One visualization will display long-term average characteristics of the water balance in the plant-soil-atmosphere system at the site of the sensor. Long-term monthly mean values of potential evapotranspiration, actual evapotranspiration, rainfall, and mean daily temperature which together defines periods in the year with specific soil hydrologic situations such as water surplus, water utilization, water deficit, and water recharge having a potential impact on cultivated plants/agroecosystems. Other ecological interpretations of the measured soil moisture will display the temporal record of actual soil moisture in the top-most soil layer $(0-10 \mathrm{~cm})$ as measured with soil moisture sensor (volumetric \%) at the site/parcel with soil moisture measurements. There are plans to display background static values of soil moisture ecological intervals (re-calculated into volumetric \%) estimated for the soil texture class taken from the underlying soil map/grid based on GPS coordinates of the sensor.

\section{GROW gridded product visualization}

Gridded products generated from point measurements and user's land and soil observations are the visual interpretation of the collected data and the continuous extension of point measurements for the entire area of the GROW Places. The quality of the estimation for the area between measuring points depends on the distribution of the sensors and the quality of the explanatory variables (other sources of environmental data available for the relevant area). A methodology for the extrapolation of measured soil moisture data for the area of Europe will be developed, using available free source environmental data as explanatory variables. Also, measurements of the error of the estimation of values for the intervals between measuring sites will be elaborated. This will facilitate the use of GROW data in climate modelling, drought/flooding forecast or in precision agriculture. In the Miskolc area (NE Hungary) a pilot area was established for which highresolution environmental data (relief, land cover, soil, and daily meteorological data) are available. A dense network of soil moisture sensors had been set up and two months of soil moisture measurements collected. The resulting dataset was used to create a time series of a gridded product with varied density of sensor network and with different explanatory variables, for known weather events. The gridded product pilot aimed to set up the optimal distribution pattern for sensor measurements for the GROW places. This is part of the sensor distribution plan synchronized with the demands of citizen engagement. As a result of the gridded product pilot, a set of environmental variables was listed which are needed for gridded product development for GROW place areas. This visualization will be used in the engagement process.

The point soil moisture measurements gathered by the observatory are processed, analysed and interpreted. The most powerful tool for visualization is the continuous prediction map of soil moisture for the available biggest areas where the sensor spatial distribution allows. The sensor distribution plan was de- 
veloped to generate a spatially coherent, and representative sensing network. The aim is to interpolate the point information and estimate the properties for any non-visited site, create a continuous surface from the point observations. These soil moisture layers represent the final products of the monitoring system. The performance or accuracy of the estimations are functions of the spatial coverage of the point measurements and the availability of accurate, high-resolution explanatory variables. Open source environmental data is used for the soil moisture map development.

As the sensor deployment moves forward during the project, the soil moisture maps will have higher accuracy and greater spatial and temporal coverage, providing richer data over larger geographical areas and engaging more stakeholders. Some GROW participants are professional agro-producers, and this stakeholder group is interested in the spatial and temporal variability of the soil within their property. To satisfy this demand a sophisticated, artistic visualization of the data is to be provided in addition to scientifically accurate soil moisture maps.

\section{Visualization of experiment data}

The original intention was that experiment participant would be able to see their own data graphically as they submitted it. However, this proved beyond capacity within the timescales of the project. Instead, visualizations were produced by scientists during the experiment to show collective results at various stages. Thus, participants could understand that the data they submitted was of importance, and see how their own experience compared with the collective results. Productivity data were represented in simple graphs showing that polycultures tended to be more productive. In addition, animated graphics (in .gif format) were used to show maps of monthly productivity from each site for the monocultures and for the polyculture and presented side by side to allow both participants and other interested parties to watch the monthly yield data change. Here participants could see how their site compared and also see patterns e.g. earlier harvests in the
South of Europe and later harvests coming in in the North. A full report of the experiment will be described both in the scientific literature and as a public-facing accessible summary. It will be used to guide advice for growing from advocacy organizations like the Permaculture Association (Britain).

\section{Provisional results of the GROW system establishment}

1. Spatial coverage, the relation of observation network development and engagement process

A monitoring network like the GROW Observatory will have spatial biases as it relies on citizen scientists. Thus, the requirements of spatial and temporal coverage of the network need to be carefully designed with recruitment and engagement protocols. The scientific objectives within GROW, like creating a gridded soil moisture product based on citizen's observations using low cost soil moisture sensors and freely available environmental explanatory variables; and to provide an extensive dataset of in situ soil moisture observations which can serve as a reference to validate satellite-based soil moisture products and support the Copernicus in situ component set up restrictions on the areas to be sampled and strong demands on participants. The sensors must be deployed in as many different climate regimes, land cover classes, soil types and topographic positions as possible, on representative, non-urban areas and the longest time span of continuous observations are crucial providing data for climate-related applications, validation of satellite-based products and Copernicus.

Therefore, the main static scientific criteria were the followings:

- meaningful geographic coverage (climate, soil, land use, agro-technology) size approx. $50 \times 50 \mathrm{~km}$, can be described by approximately 1,000 sensors;

- soil, terrain and land use variability, with relatively large homogenous units;

- good quality environmental data (terrain, soil, and land use); 
- having a scientific institution capable of supervising the process;

- interested local organization to maintain and extend the network for later network expansion-community champion approach, demonstration $\mathrm{CO}$ network development to test the engagement, awareness raising strategies and toolsets.

However, the GROW project was initiated to demonstrate the development of soil moisture monitoring CO network. The first invitation round resulted in several scientifically appropriate areas, a good pool to choose the Grow areas. Thus, the first priority area list has been refined based on the need to have a strong and reliable partnership between a GROW partner and the local community champion. A strong relationship of the local community with the GROW consortia also can support good quality local environmental data (terrain, soil, land use) availability.

To achieve the best selection, a clusterednested sampling strategy was developed to cover most of the geographical diversity for the area of Europe. In parallel with the exploration of potential communities, GROW Places had been designated based on the Köppen-Geiger climate classification to cover the most of climatic homogeneity within the area of Europe. GROW Places are geographic focus areas where a high quantity of Flower Power sensors is deployed to record soil moisture and associated data at a high density of observations. They are in specific areas in Europe with strong stakeholder buy-in. The originally selected 17 priority areas covered 4 dominant climate classes: Cold, without dry season, warm summer; Temperate, without dry season, warm summer; Temperate, dry summer, hot summer; Temperate, without dry season, hot summer.

Sentinel-1 ground truthing for soil moisture modelling requires further restrictions of the sensor placement. The reliability of remotely sensed soil moisture products is influenced by the presence of water bodies and rough topography. Thus, GROW places with a smooth topographical surrounding and a low percentage of water bodies are favoured. For each GROW places ancillary dataset were used to derive topographic complexity and wetland fraction at the scale of a satellite footprint (Dorigo, W.A. et al. 2015), but this selection was used only as a starting point to contact local communities and start concrete discussions about the implementation of the GROW places. From that contact round, it became clear that some of the selected GROW places had to be updated and others replaced as no supporting communities could be identified. An enthusiastic community champion is a key to the success of continuous data collection. The scientific criteria were not used to select GROW places but were used to evaluate them, especially new GROW places. When adding new GROW places, only the climatic zone criteria were used to evaluate the relevance of the geographic location of the proposed locations. The engagement process outputs were placed as the first priority, and provided with a set of real GROW places, with committed local actors. A wide range of the European climate regions, land use types and topography are covered by the eight final GROW places: Evros and Laconia (Greece), Southeast and Northwest Ireland, Miskolc (Hungary), Barcelona (Spain), Algarve / Alentejo (Portugal), Tayside and Central Belt (Scotland), Vienna (Austria), 's-Hertogenbosch (Netherlands), and Luxembourg.

Within the regional level, there are the nested dense observation clusters representing the local diversity of soil, land use, and topography. This usually covers 40 to 1,500 hectares with high sensor density. Here stakeholders are communities of sustainable growing practices or agricultural producers with economic interest or research institutions. These dense sampling networks are complemented by observation points in between covered by smaller-scale growers with few sensors deployed.

The primary demographic of GROW is small-scale growers, professionals, and hobbyists, who were expected to be financially independent, intellectually curious and emotionally connected to growing. One strong 
motivation for joining a growing community is found in the common need of living in a sustainable and harmonious environment close to and minimize harm to nature. The overall communication and engagement strategy and toolset were developed to reach out to this type of audience.

2. Piloting engagement and sensing network development

To test engagement tools and procedure within the constraints of the scientific criteria three pilot missions were set up on GROW places: Alexandroupolis (Greece), Cloughjordan (Ireland) and Miskolc (Hungary), where project partners were involved. The main objectives of the pilot missions were:

- to validate scientific usefulness of the data through satellite validation activities and preliminary gridded products production; - to validate the material, protocols, and instructions for citizens to deploy, and to maintain the sensing network from a scientific point of view;

- testing local aspects of the engagement protocol (participant pathway, community champions) for engaging participants within the project;

- validating that the growers are able to take benefits of the sensors and additional activities, and to test GROW's back end system and its capacity to collect and provide the data to users. The missions were implemented by project partners from participant recruitment through workshops and training and sensor deployment.

One very important point to note about the pilots is even with well-developed engagement tools, it can be difficult to implement on a local scale. GROW Places are large areas throughout Europe, where social, demographic and economic differences result in the different target audience and require different ways of communicating and training. The overall strategy and tools can result in different levels of engagement and generated data quality depending on location. Global tools are for highlighting the aims and objectives but the local organizing force is indispensable.
With small-scale growers, the emotional connection to their work is strong and engagement is possible through workshops and awareness raising. This demographic is motivated to observe their soil and environment, but the number of sensors available for them to deploy is very limited, therefore, spatial coverage is random and dispersed if there is no community for a local clustering role. Thus, the database resulting from these observations is not suitable for growing consultancy, nor for validating that the growers are able to take benefits of the sensors.

Technical difficulties influence the extent and speed of engagement. GROW aims to deploy 15,000 relatively low-cost commercial soil moisture sensors. The commercial product contains all backend services of data download, storage, and query which is provided for all participants of the project. Sensor usage training is limited to the operation of the plug-and-play product. Even with these limits in place, during the pilot missions continuous technical support was needed for sensor deployment, data upload and data connection to $\mathrm{CH}$. Small scale growers, using a small number of sensors, may face problems with the technical infrastructure and on occasion need personal assistance. It is not feasible to address these issues and to support participants on an individual basis, although emerging problems are unique.

One important issue noted within this project, the extent of which is heterogeneous throughout Europe, is the physical security of properties. The North East Hungarian pilot faced serious problems of sensor disappearance by theft. This is a very limiting factor of spatial and temporal coverage. As an example of specific land use, in vineyards where harvesting is carried out by contracted seasonal workers be monitored during harvest time, sensors must be removed for the period of one to months. Unfortunately, when the sensors are not deployed over the late summer and early autumn, it is not possible to provide important data on the phenological state of the grapevines in preparation for the winter. Soil moisture over this time period is impor- 
tant for the vines' nutrient uptake, and, thus, heavily influences the force of sprouting in springtime. So, important data with forecasting potential is lost as a consequence of having to remove the sensors during harvesting.

As the project aims to set up a long-term, self-sustained $\mathrm{CO}$ during the funding period, the time-frame of engagement and sensor deployment is limited. With sufficient professional and economic interest from agricultural producers and scientific researchers, sensor deployment could be accelerated to ensure high quality, reliable and continuous observations. Communication towards these potential stakeholders was only undertaken by project partners, with no general communication and engagement strategy developed.

GROW's science partner responsible for the gridded product development and data quality (University of Miskolc), set up a pilot mission with two professional stakeholder companies, with whom previous research collaboration had been established prior to GROW. The pilot areas cover two different land uses: vineyard and arable land. High sensor density provides data from representative sites of soil and topography. To set up the monitoring network, the science partner deployed the sensors based on high resolution local environmental data and empirical knowledge. Regular readings are implemented by researchers with the help of the stakeholders, and harmonization of the data needs of producer and research is being undertaken. Continuous effort is made to generate an up-to-date operative database for professional agricultural decision-making and research purposes.

One important issue is the frequency with which the sensor data is uploaded into the database. Retrospective access to the database can still be of use for scientific research, but agricultural consultancy requires a regularly updated database. The fundamentals of an operational up-to-date monitoring system that can provide data for agricultural consultancy and forecasting, must be set up with scientific vigour and needs an extensive infrastructure of sensors and data storage and processing and a technical front end application to serve decision making.

\section{Conclusions, achievements and challenges identified}

One of the important roles of the GROW project has been to set up standards and protocols for soil moisture monitoring carried out by citizen observation networks, to meet scientific and professional criteria. Science protocols are set, harmonization with professional agricultural needs is being implemented in the second half of the project. Science can provide data quality assurance and reliable data interpretation, but a functioning $\mathrm{CO}$ gives the platform to science to create data interpretation useful for citizens. However, along with the advantages and potentials of the $\mathrm{CO}$ approach, several challenges have been identified as well.

One of the most important findings is that the results of 100 years of public awareness raising and tradition, like the bird watching example or the weather watchers, is difficult to replicate within a few years. Huge efforts are needed for topics like soil moisture to be integrated into common societal knowledge. Awareness raising and public engagement strategy development are the two most critical elements of any success, where top-down efforts supported by policy-making can make a difference.

Data representativity is also a relevant issue. A good monitoring system needs to cover all different kinds of environmental settings, defined by geomorphological, land use and soil properties - among others. A system targeting small-holders may result in a spatially biased, incomplete distribution of the monitoring sites, where the point density is high within the village and low or even zero for areas outside of the villages. The soils of the small-holders garden are often changed by cultivation, artificial additives, therefore, the point may represent only a small neighbourhood, extrapolation of its information is often limited.

One potential means to accelerate the development of a high-quality soil moisture monitoring system in Europe is to move towards engaging with large-scale agriculture, 
which would require an increasing interest in maintaining soil moisture monitoring systems provide public data. Such a reliable data source could catalyse break-through in all the disciplines affected in earth observation, climate modelling and precision soil and land management and use. The GROW project as a top-down initiative funded by the European Commission has the potential to initiate these necessary processes. With the tools of engagement, communication, training and awareness raising enforces the bottom-up development of the $\mathrm{CO}$, reaching out to the widest spectra of interested stakeholders. This catalyses self-organizing data communities with the interest in soil monitoring, which through open source APIs and DIY sensors can develop sensing and data infrastructure, or economic interest sets up professional networks with researchers. Based on the pilot missions' experiences GROW involved larger scale agriculture and research institutions in the targeted audience. DIY sensor knowledge base and an API to connect any soil sensors to the GROW Collaboration Hub had been developed and will be communicated to the end of the project.

A major finding of the GROW project is that low-cost soil moisture sensors can provide data both for home and for scientific use. However, some conflicts between the home user and the scientific interest have been identified. Sentinel-1 data is sensitive to soil moisture of the upper 10 centimetres. This layer dries out and can be rewetted fast. The layer directly below the soil surface represents a more stable source of available water for the plants. Therefore, sensors deployed under the surface layer would provide more relevant information for the grower, but less representative for the Sentinel-1 data validation and calibration.

It has been concluded, that these low-cost sensors have a relatively good performance. The comparison of several readings from the different sensors within the same condition was quite consistent. However, a significant deviation from the lab measurements was identified, probably due to the built-in soil moisture estimation algorithm. It is known, that different soils have different relationships between their dielectric constants and their soil moisture content, so different estimation algorithms need to be fitted to different soils. Any common platform aiming to integrate different sources of data should take the direct raw measurement and apply the appropriate algorithm afterward to avoid inconsistency due to the different estimation algorithms applied within the different kinds of sensors.

The ground truthing of the Sentinel-1 soil moisture model's main criteria is the availability of fresh, up to date data. In order to develop a close to real-time, operational data platform providing up to date soil moisture estimations need to have more frequent data upload to the server. The strong interest of data providers to ensure frequent data upload is the issue to emphasize. Besides of the traditional engagement mechanisms described in this paper, other innovative approaches for better outreach to the society, like the integration of environmental art to catch broader community attention is also initiated and currently being developed.

A well-functioning back end system of sensing, data storage and visualization can provide a stable environment for database continuity. A good visualization of data is an important tool for science to develop data interpretation based on professional agricultural needs.

GROW must emphasize awareness-raising, communication, and engagement for the widest range of audience. The post-funding sustainability of the $\mathrm{CO}$ depends on the sustaining of both the communities and the infrastructure of sensing, data logging, and processing and interpretation. An engagement tool for stakeholders interested in the technical part of soil-sensing is being developed and communicated in the second part of the project. This must be emphasized because DIY sensors and open source communities can provide self-organizing infrastructure for soil moisture monitoring. An existing infrastructure of observations is more likely to generate data interpretation and visualization which is attractive and engaging for a wide audience and encourage participation. 
Acknowledgements: This project has received funding from the European Union's Horizon 2020 research and innovation program under grant agreement No. 690199.

\section{REFERENCES}

Bauer-Marschallinger, B., Freeman, V., CaO, S., Paulik, C., Schaufler, S., Stachl, T. and Wagner, W. 2018. Toward global soil moisture monitoring with Sentinel-1: Harnessing assets and overcoming obstacles. IEEE Transactions on Geoscience and Remote Sensing 57. (1): 520-539. Available at: https://doi. org/10.1109/TGRS.2018.2858004

Blöschl, G., Blaschke, A.P., Broer, M., Bucher, C., Carr, G., Chen, X. and Zessner, M. 2016. The hydrological open air laboratory (HOAL) in Petzenkirchen: A hypothesis-driven observatory. Hydrology and Earth System Sciences 20. (1): 227-255. Available at: https://doi.org/10.5194/hess-20-227-2016

Bonney, R., Cooper, C.B., Dickinson, J., Kelling, S., Phillips, T., Rosenberg, K.V. and Shirk, J. 2009. Citizen science: A developing tool for expanding science knowledge and scientific literacy. BioScience 59. (11): 977-984. Available at: https:// doi.org/10.1525/bio.2009.59.11.9

Brocca, L., Hasenauer, S., Lacava, T., Melone, F., Moramarco, T., Wagner, W., Dorigo, W., Matgen, P., Martínez-Fernández, J., Llorens, P., Latron, J., Martin, C. and Bitelli, M. 2011. Soil moisture estimation through ASCAT and AMSR-E sensors: an inter-comparison and validation study across Europe. Remote Sensing of Environment 115. 3390-3408. DOI: 10.1016/j.rse.2011.08.003

Butcher, G.S., Fuller, M.R., McAllister, L.S. and Geissler, P.H. 1990. An evaluation of the Christmas bird count for monitoring population trends of selected species. Wildlife Society Bulletin 18. 129-134.

Chan, S.K., Bindlish, R., O'Neill, P.E., NuOKu, E., Jackson, T., Colliander, A. and Kerr, Y. 2016. Assessment of the SMAP passive soil moisture product. IEEE Transactions on Geoscience and Remote Sensing, 54. (8): 4994-5007. Available at: https://doi. org/10.1109/TGRS.2016.2561938

Clary, E.G. and SNYDer, M. 1999. The motivations to volunteer. Current Directions in Psychological Science 8. (5): 156-159. Available at: https://doi. org/10.1111/1467-8721.00037

Dorigo, W.A., Gruber, A., De Jeu, R.A.M., Wagner, W., Stacke, T., Loew, A., Albergel, C., Brocca, L., Chung, D., Parinussa, R.M. and Kidd, R. 2015. Evaluation of the ESA CCI soil moisture product using ground-based observations. Remote Sensing of Environment 162. 380-395.

Dorigo, W.A., van Oevelen, P., Wagner, W., Drusch, M., Mecklenburg, S., Robock, A. and Jackson, T. 2011a. A new international network for in situ soil moisture data. Eos Transactions AGU 92. (17): 141-142.

Dorigo, W.A., Wagner, W., Hohensinn, R., Hahn, S., Paulik, C., Drusch, M., Mecklenburg, S. and Xaver, A. 2011b. The International Soil Moisture Network: A data hosting facility for global in situ soil moisture measurements. Hydrology and Earth System Sciences 15. (5): 1675-1698.

Dorigo, W.A., Xaver, A., Vreugdenhil, M., Gruber, A., Hegyiová, A., Sanchis-Dufau, A.D., Zamojski, D., Cordes, C., Wagner, W. and Drusch, M. 2013. Global automated quality control of in situ soil moisture data from the International Soil Moisture Network. Vadose Zone Journal 12. (3): 1-21. DOI: 10.2136/vzj2012.0097

Freitag, A., Meyer, R. and Whiteman, L. 2016. Strategies employed by citizen science programs to increase the credibility of their data. Citizen Science: Theory and Practice 1. (2): 1-11.

Geoghegan, H., Dyke, A., Pateman, R., West, S. and Everett, G. 2016. Understanding motivations for citizen science. Final report on behalf of UKEOF, University of Reading, Stockholm Environment Institute, University of York and University of the West of England. Swindon, UKEOF Natural Environment Research Council.

Gharesifard, M., Wehn, U. and van der ZaAg, P. 2017. Towards benchmarking citizen observatories: Features and functioning of online amateur weather networks. Journal of Environmental Management 193. 381-393. Available at: http://doi.org/10.1016/j.jenvman.2017.02.003

Grainger, A. 2017. Citizen observatories and the new earth observation science. Remote Sensing 9. 153-153.

Gruber, A., Dorigo, W.A., Zwieback, S., Xaver, A. and WAGNER, W. 2013. Characterizing coarsescale representativeness of in situ soil moisture measurements from the International Soil Moisture Network. Vadose Zone Journal 12. (2): 1-16. DOI: 10.2136/vzj2012.0170

Hecker, S., Haklay, M., Bowser, A., Makuch, Z., Vogel, J. and Bonn, A. 2018. Citizen science innovation in open science and policy. UCL Press. Retrieved from https://www.ucl.ac.uk/ucl-press/browsebooks/citizen-science

Носнаснка, W.M., Fink, D., Hutchinson, R.A., Sheldon, D., Wong, W.K. and Kelling, S. 2012. Data-intensive science applied to broad-scale citizen science. Trends in Ecology and Evolution 27. (2): 130-137.

IPCC 2007. Summary for Policymakers. In Climate Change 2007: The Physical Science Basis. Contribution of Working Group I to the Fourth Assessment Report of the Intergovernmental Panel on Climate Change. Cambridge, UK and New York, USA, Cambridge University Press. 
Kerr, Y.H., Waldteufel, P., Richaume, P., Wigneron, J.P., Ferrazzoli, P., Mahmoodi, A. and Delwart, S. 2012. The SMOS soil moisture retrieval algorithm. IEEE Transactions on Geoscience and Remote Sensing 50. (5): Part 1. 1384-1403. Available at: https://doi. org/10.1109/TGRS.2012.2184548

Lavelle, P., Decaëns, T., Aubert, M., Barot, S., Blouin, M., Bureau, F. and Rossi, J.P. 2006. Soil invertebrates and ecosystem services. European Journal of Soil Biology 42. (Suppl. 1) 3-15. Available at: https://doi.org/10.1016/j.ejsobi.2006.10.002

LiU, H.Y., Kobernus, M., Broday, D. and Bartonova, A. 2014. A conceptual approach to a citizens' observatory - supporting community-based environmental governance. Environmental Health 2014 Dec 12;13:107. DOI: 10.1186/1476-069X-13-107.

Makó, A., Tóth, B., Hernádi, H., Farkas, Cs. and MARTH, P. 2010. Introduction of the Hungarian detailed soil hydrophysical database (MARTHA) and its use to test external pedotransfer functions. Agrokémia és Talajtan 59. (1): 29-38.

McGlade, J. 2009. Global citizen observatory - The role of individuals in observing and understanding our changing world. Annual Earthwatch lecture - Citizen Science, Oxford, 16 $6^{\text {th }}$ February 2009.

Mohanty, B.P., Cosh, M.H., Lakshmi, V. and MontzKa, C. 2017. Soil Moisture Remote Sensing: State-of-the-Science. Vadose Zone Journal 16. DOI: 10.2136/vzj2016.10.0105.

Morbidelli, R., Saltalippi, C., Flammini, A., Rossi, E. and Corradini, C. 2014. Soil water content vertical profiles under natural conditions: Matching of experiments and simulations by a conceptual model. Hydrological Processes 28. (17): 4732-4742. DOI: 10.1002/hyp.9973.

Pocock, M.J.O., Twedle, J.C., Savage, J., Robinson, L.D., Roy, H.E. and Crownston, K. 2017. The diversity and evolution of ecological and environmental citizen science. Plos One 12(4), e0172579. Available at: http://doi.org/10.1371/journal.pone.0172579
Robinson, D.A., Campbell, C.S., Hopmans, J.W., Hornbuckle, B.K., Jones, S.B., Knight, R., Ogden, F., Selker, J. and Wendroth, O. 2008. Soil moisture measurement for ecological and hydrological watershed-scale observatories: A review. Vadose Zone Journal 7. 358-389.

Rotman, D., Preece, J., Hammock, J., Procita, K., Hansen, D., Parr, C. and Jacobs, D. 2012. Dynamic changes in motivation in collaborative citizenscience projects. Proceedings of the ACM 2012 Conference on Computer Supported Cooperative Work - CSCW '12, 217. Available at: https://doi. org/10.1145/2145204.2145238

Várallyay, G. 1989. Soil Mapping in Hungary. Agrokémia és Talajtan 38. 696-714.

VÁrAllyay, G. 1994. Soil database for long-term field experiments and sustainable land use. Agrokémia és Talajtan 43. 269-290.

VÁrallyay, G. 2010. The increasing importance of the water storage function of soils under climate change. Agrokémia és Talajtan 59. (1): 7-18.

Wagner, W., Hahn, S., Kidd, R., Melzer, T., Bartalis, Z., Hasenauer, S. and Rubel, F. 2013. The ASCAT soil moisture product: A review of its specifications, validation results, and emerging applications. Meteorologische Zeitschrift 22. (1): 5-33. Available at: https://doi.org/10.1127/0941-2948/2013/0399

WANG, L. and Qu, J.J. 2009. Satellite remote sensing applications for surface soil moisture monitoring: A review. Frontiers of Earth Science in China 3. (237): 237-247. Available at: https://doi.org/10.1007/ s11707-009-0023-7

West, S.E. 2015. Understanding participant and practitioner outcomes of environmental education. Environmental Education Research 21. (1): 45-60. 
